\title{
Designing Interfaces for Creative Learning Environments Using the Transreality Storyboarding Framework
}

\author{
Jazz Rasool \\ Ravensbourne University London \\ 6 Penrose Way, Greenwich Peninsula \\ SE10 OEW London, UK \\ +44 (0) 2030403500 \\ j.rasool@rave.ac.uk
}

\author{
Judith Molka-Danielsen \\ Molde University College \\ Britvn 2, Postboks 2110 \\ 6402 Molde, NOR \\ +4771214239 \\ j.molka-danielsen@himolde.no
}

\author{
Carl H. Smith \\ Ravensbourne University London \\ 6 Penrose Way, Greenwich Peninsula \\ SE10 OEW London, UK \\ +44 (0) 2030403500 \\ c.smith@rave.ac.uk
}

\begin{abstract}
Modern creatives, producing different media within multiple mediums, could benefit from transmedia-based methodologies that ensure core standards in effective interface design and storyboarding adopted in the production of creative works. This is relevant for students learning creative disciplines and professionals prototyping briefs within the creative industries. Students and professionals must learn to creatively fulfil a brief, express a story or narrative in a transmedia experience space that employs three components that work with different realities, senses and interactions. An approach addressing these components is formalised by the authors into the Transreality Storyboarding Framework (TSF). The first component maps eight realities that students must learn to tell stories across, the Eight Realities Design Methodology (ERDM). The second component, (PAIRS), focuses on the design of user interfaces and experiences (UI/UX) connecting people into creative works, exploring the inclusion of Passive, Active, Interactive, Responsive and Shared interactions. The third component is Contextology, a methodology for exploring how different kinds of senses engage with the narrative within those creative realities. Case studies in Architecture, Art \& Design, Engineering, Training as well as Fashion are reviewed showing how workflows used aspects of these approaches for effective storytelling and engaging creative and educational experiences.
\end{abstract}

\section{CCS Concepts}

- Human-centred computing $\rightarrow$ Interaction Design $\rightarrow$ Interaction design process and methods $\rightarrow$ Contextual design

\section{Keywords}

Human-centred; Transmedia; Transreality Storyboarding Framework; Eight Realities Design Methodology; Contextology; Context Engineering; Interaction Design

\section{INTRODUCTION}

Students in the design industries (e.g. fashion, architecture, media, design, etc.) must be primed to work in modern creative

Permission to make digital or hard copies of part or all of this work for personal or classroom use is granted without fee provided that copies are not made or distributed for profit or commercial advantage and that copies bear this notice and the full citation on the first page. Copyrights for third-party components of this work must be honored. For all other uses, contact the Owner/Author.

$B D E$ 2020, May 29-31, 2020, Shanghai, China

(C) 2020 Copyright is held by the owner/author(s).

ACM ISBN 978-1-4503-7722-5/20/05.

DOI: https://doi.org/10.1145/3404512.3404530 environments. Before graduating, a fundamental requirement is to be educated and experienced in a minimum set of creative production techniques and technologies - realities that include illustration, 3D computer modelling as well as immersive realities such as Augmented and Virtual Reality. To complement this, they will also work with media that relate and connect with different senses, creating assets such as visual, audio and haptic media. In addition, modes of interaction with their creative work must be carefully selected, assigned and integrated to ensure an engaging experience of the narrative, storytelling or message behind their work; the modes of interaction therefore act as the bridge between the realities and senses.

\subsection{Challenges in Formulating A TSF}

Initial attempts were made by the research team at producing a framework to help designers use a more coherent encompassing design, production and management framework for their works focused on strategies for working across mediums or realities such as Computer Aided Design, 3D Printing as well as Augmented Reality, Virtual Reality and Mixed Reality. This produced a methodology, the Eight Reality Design Methodology (ERDM) for managing narrative and production across eight realities. There were two challenges with this methodology. The first challenge was ERDM had no formal inclusion of User Interface (UI) or User Experience (UX) affordances. Existing UI/UX design strategies were an obstacle to integration, as they did not fully cater for common interfaces across multiple mediums or realities. Secondly, the ERDM approach, although it referenced adoption of media utilising sensory channels, it offered no formal framework for doing so. After considering UI/UX approaches it was found that five types of interaction or interface were used in creative works that spanned multiple realities or sensory media. To address the first challenge, the five types of interaction, their mutual relationships and their contribution to interface design were compiled into a custom framework, called PAIRS, that would formally classify UI/UX interactions/interfaces as well as their modes of adoption. To address the second challenge of formally mapping sensory channels to media and mediums, an existing framework, Contextology, that formally treated sensory channels and their utilisation in modern media and technology. The component frameworks, ERDM, PAIRS and Contextology were seen to complement one another and were subsequently integrated under a new single, unified and more coherent parent framework, the Transreality Storyboarding Framework.

\subsection{The TSF Components}

The Transreality Storyboarding Framework (TSF) has three components that help designers follow comprehensive production strategies that serve modern creative pipelines and deliver aesthetic and technical excellence as well as strong narrative alignment: 
1. Eight Realities Design Methodology (ERDM). Observing creative outputs over many years and projects, eight fundamental mediums were found to be engaged with including traditional mediums such as paper illustration, computer based designs as well as modern mediums such as 3D Print, Augmented Reality and Virtual Reality. These eight realities were mapped into ERDM.

2. PAIRS. Identifies needed user interface support for connection/interactions with the learning environment (passive, active, interactive, responsive and shared). The PAIRS methodology maps considerations that have arisen for an interface between mediums (realities) and media (sense) which will afford specific interactions that users will have with the generated experiences. In this way PAIRS acts as an interface between ERDM and Contextology.

3. Contextology. This methodology profiles the user senses (hearing, seeing, touching, etc.) that are intended to be activated during an interaction. This is in order to make visible what their resulting contribution to the meta level view of the desired experience, its context, will be. The sensory channels that need to be targeted have aligned media assets created for them. This includes creating assets that utilise vision, sound and haptic (touch) channels, our sense of time and space as well as sensory data generated from modern electronic sensors. Contextology compiles all of these elements into a strategy that maps sensory engagement and their ultimate utilisation within creative media.

The dimensions and constraints of the creative space produced by integrating ERDM, PAIRS and Contextology into the Transreality Storyboarding Framework is shown in Figure 1. TSF contributes to creating traditional, tangible creative outputs existing in the real world as well as virtual, mixed reality technology (XR) outputs that are key to enabling effective learning experiences.

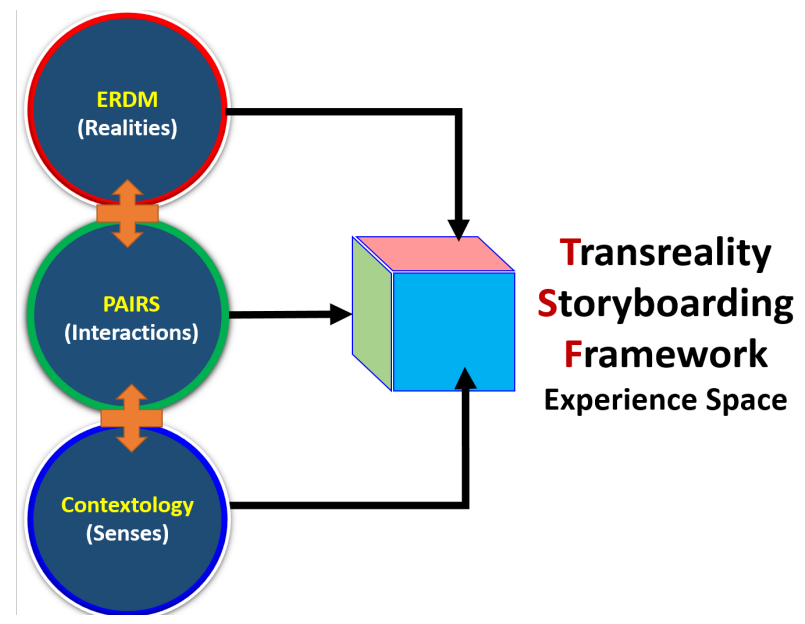

Figure 1. Designing interfaces for creative learning environments using the Transreality Storyboarding Framework

In this paper, we begin by presenting the story of the development of the Eight Realities Design Methodology (ERDM), which was motivated by the needs of educators in the creative design industries. We analysed the methodology, through a case study, exploring a workflow, which was produced to take Leonardo da Vinci's sketches for perpetual motion machines in order to generate immersive experiences of them with mixed reality devices. The application of the TSF for designing interfaces for creative learning environments is demonstrated through the case studies of learning experiences introduced in Section 4.
TSF can assist educators to inform HCI and UX designers to the types of interfaces and interactions that may be required or desirable within the learning experience. In addition, TSF can help designers by raising awareness around the elements that are currently lacking in educational HCI and UX designs.

\section{LITERATURE REVIEW}

User engagement is seen as a critical element for learning. Engagement can be defined as a quality of the user's experience, the attributes which will differ individually, but are tied intricately to factors of the user's perception and attention. Perception is how we sense our environment and construct a mental representation and the impact of one's sensations based on previous knowledge or expectations. Attention entails allocating cognitive resources to inputs and processes, while possibly ignoring other inputs.

In recent years the designers of games, including serious games for learning, have identified the concept of engagement as keeping the user in the "flow" state. Csíkszentmihályi introduced the concept of "flow" in his 1990 seminal work [1]. He describes the optimal experience of a user as the cognitive state between anxiety and boredom. In this state, the user's sense of time can be transformed, and they can experience a particular state of concentration on the task at hand. Research indicates that when users are in a state of flow they aren't attending to the technology or its functioning; they are attending to the task at hand alongside a feeling that progress is being made toward their end-goal [2]. In experiments on flow and learning in games, it was found that flow is a very individual characterisation, and specifically, more experienced users of a particular task may be able to take on more difficult challenges [3].

The state of flow and engagement can be tightly intertwined with an individual's sense of perception. The new paradigm of Context Engineering (CE) [22] focuses on how we can make our own perception the 'content'. This reflects the ongoing trend that the lenses through which we experience the world are becoming more adjustable than ever. CE gives us new abilities, control over our senses and the ability to develop new forms of perception, providing us with a new type of self, expression and learning.

Contextology is the study of context, the science of Context Engineering. Contextology examines how interaction between contexts results in synthesis and the emergence of the new. Specifically, Contextology focuses on the role of human agency in the interplay of generating new internal (subjective) and external (objective) contexts and thereby realities [23]. This is important for our Transreality Storyboarding Framework (TSF) precisely because this re-definition of internal contexts (subjective perceptions) is now more broadly accessible through the use of contemporary Augmented Reality and Virtual Reality technologies more commonly placed under the umbrella term, Extended Reality (XR).

Pioneer research [23], in Contextology, argues that 'reconfiguring our own perception (individually or in groups) as the primary content' and extending our senses of the external contexts establishes a nexus for an agency driven dialectic between the newly developed internal context (perceptions) and the external contexts to which they pertain. Specifically, newly exposed information about external contexts that are comprehensively sensed within internal contexts will lead to new classes of innovation in the creation and engineering of external contexts, elements that are central to the design of UX for learning. In other words, if we can fundamentally change the way we percieve the world through the adoption of new senses, then it is vital that the field of HCI also grows in accordance with that development. 
In a meta-study of UX frameworks and models, the authors identified that UX interface designs should include elements for evaluation of presence (physical and social), cognitive evaluation (involvement, time) and emotional evaluation (emotional outcomes, appeal) [4]. These elements can influence users personally and socially. More specific social elements impacting user experience evaluations were found to be political, cultural and economic. Physical elements were found to involve technology, geography, demographic, and architecture. This informs us that human experience is both a personal and social multi-modal phenomena. Any attempt at modelling this and capitalising on it to enhance and sustain creativity must be a multimodal process. Multimedia production follows a workflow sequence of discovering and developing mindset, techniques and technology, especially the process of Transmedia storytelling and production, so this would be a good entry point to initiate exploration of potential frameworks.[5][6].

Jenkins introduced the concept of Transmedia Theory, or also called Transmedia Storytelling, as a multi-channel or multiplatform approach to enhance storytelling. He described it as a cocreation model for the adaption of content to be consumed across media [5][6]. Dena investigated a multi-channel paradigm, and made the distinction of structures in that, a story as adapted in different channels is a cross-media expression, and the story if spread through different channels is a transmedia phenomena [7]. Both definitions of transmedia storytelling seem to focus on the output expression of the story. In the creation of stories the story may be disjointed in some cases. As Jenkins pointed out, the story of a Marvel Universe character may be expressed in various media (e.g. film, graphic novel, video game, etc.) where the design processes have no connection with each other. Other research has indicated that transmedia storytelling has too strong a focus on authorship, and does not offer enough tools to designers for evaluating experiences in transmedia designs [8]. We propose therefore, that there is a need for a framework to envision a story through a user perceived experience space and that would aid in the design of creative learning spaces. Museums, in the curation and design of artifacts are increasingly applying multi-channel approaches [10][11][20][21]. Future research of curation in such environments will prove useful in gathering some initial guiding principles of transmedia storytelling that may set the foundations for transreality workflows.

\section{EMERGENCE OF TSF COMPONENTS}

The Transreality Storyboarding Framework had four prior learning experiences of workflows that informed its current structure, a presentation at a Fashion conference, an Architecture paper, an Art $\&$ Design installation and a project focused on training with $\mathrm{AR}$ technologies. The emergence of the components of TSF are introduced in this Section 3. Later, in Section 4 Tables 2, shows how each of these components are utilised in TSF is covered.

\subsection{Evolution of the Eight Realities}

From 2017 to 2019 different families of creative mediums or realities were applied in creative projects, beginning with a Four Reality approach that advanced into a Six Reality approach and finally formed into the Eight Reality Design Methodology. All three stages of development of the ERDM received expert guidance from the first author.

Four Reality Fashion Design Strategy. In 2017, Caroline Gilbey, Associate Dean of Fashion at Ravensbourne University London followed the guidance on how to combine a workflow covering the arc of realities between Real World physical production (Everyday
Reality) of fashion garments, 3D Printing of scanned models wearing garments, Augmented Reality view of the models as well as a fully immersive Virtual Reality experience of the garment. Gilbey presented this work at the International Conference on Apparel Textiles and Fashion Design in Sri Lanka, August 2017.

Six Reality Architecture Workflow. In November 2017, Idrees Rasouli, course leader in Architecture at Ravensbourne University London, wanted to include illustration and imagination as examples of realities utilised by Architects. The first author suggested including these in addition to the existing four proposed for Gilbey. The result was a six reality teaching framework for the study of architectural heritage and their use in the transformation of existing buildings that was presented at a conference in Dubai, 2017.

Table 1. The Eight Realities involved in Creative Production workflows [13]

\begin{tabular}{|c|c|}
\hline $\begin{array}{l}\text { Reality } \\
\text { Type }\end{array}$ & Meaning/Implication \\
\hline $\begin{array}{l}\text { Everyday } \\
\text { Reality }\end{array}$ & $\begin{array}{l}\text { The real world, subject to forces of nature, that } \\
\text { people can learn about directly without any } \\
\text { aids other than their own senses. }\end{array}$ \\
\hline $\begin{array}{l}\text { Imaginary } \\
\text { Reality }\end{array}$ & $\begin{array}{l}\text { An internalised version of the real world is a } \\
\text { person's imaginary world where they dream } \\
\text { and create. }\end{array}$ \\
\hline $\begin{array}{l}\text { Drawn/ } \\
\text { Captured } \\
\text { Reality }\end{array}$ & $\begin{array}{l}\text { Capturing a view, mental or external as } \\
\text { drawing, painting, photograph or a } 3 D \text { Scan } \\
\text { can be another way to portray the world. } \\
\text { Sequences can be made into an animation, a } \\
\text { motion picture, video or a } 3 D \text { digital model. }\end{array}$ \\
\hline $\begin{array}{l}\text { Computer/ } \\
\text { Electronics } \\
\text { Aided } \\
\text { Reality }\end{array}$ & $\begin{array}{l}\text { Portraying an idea on a two dimensional } \\
\text { screen such as a TV screen, or computer } \\
\text { monitor using Computer Aided Design } \\
\text { software. }\end{array}$ \\
\hline $\begin{array}{l}\text { 3D Printed } \\
\text { Reality }\end{array}$ & $\begin{array}{l}\text { Print into physical form using a 3D printer in } \\
\text { plastic, powdered stone, wood and even metal. }\end{array}$ \\
\hline $\begin{array}{l}\text { Augmented } \\
\text { Reality }\end{array}$ & $\begin{array}{l}\text { A mobile device can have the view from an } \\
\text { onboard camera overlaid with digital content } \\
\text { such as text, image, a } 3 \mathrm{D} \text { model, video, } \\
\text { animation or an interactive element. }\end{array}$ \\
\hline $\begin{array}{l}\text { Virtual } \\
\text { Reality }\end{array}$ & $\begin{array}{l}\text { An artificial generated digital environment } \\
\text { with no direct sensory connection to everyday } \\
\text { reality. A binocular / stereoscopic virtual } \\
\text { reality headset can provide a computer- } \\
\text { generated reality }\end{array}$ \\
\hline $\begin{array}{l}\text { Extended/ } \\
\text { Holographic } \\
\text { Reality }\end{array}$ & $\begin{array}{l}\text { Headsets such as the Microsoft Hololens have } \\
\text { transparent lenses placed in front of each eye } \\
\text { through which everyday reality can be seen. } \\
\text { Imagery can be projected onto the lenses to } \\
\text { give the impression of content being present in } \\
\text { the everyday reality. }\end{array}$ \\
\hline
\end{tabular}

Eight Reality Art \& Design Installation. In 2019, the first author helped curate an Art \& Design installation celebrating the 500th Anniversary of Leonardo Da Vinci's death. Da Vinci's illustrations for perpetual motion machines were turned into Mixed Reality 
experiences. The expansion of the six reality methodology implemented in this Art \& Design installation was documented into the Eight Realities Design Methodology (ERDM). The eight realities are described in Table 1 .

Design students need to gain competencies along a trans-reality arc of learning from Everyday Reality to Extended/Holographic Reality (e.g. following the left arc in Figure 2) in order to claim proficiency in creative and technical production competencies while enhancing their ability to fully express within their creative domain. Not all creations will necessarily be expressed in or across all of the eight realities. For example, an architect may choose to focus on a design and production workflow expressed from Everyday Reality to Augmented Reality (e.g. following the right arc in Figure 2) and outsource Virtual or Holographic rendering of designs.

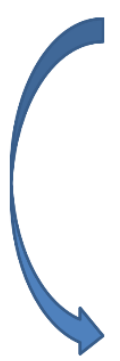

1. Everyday Reality.

2. Imaginary Reality.

3. Drawn/Captured Reality.

4. Computer/Electronic Aided Reality.

5. 3D Printed Reality.

6. Augmented Reality.

7. Virtual Reality.

8. Extended/Holographic Reality.

Figure 2. Eight Realities Design Methodology (ERDM): Educational Workflow [19]

The ERDM became a workflow that designers and creatives could use to develop skills for use in the creative industries through a process of incrementally expanding dimensions, mediums, fidelity and sharing. This workflow is described in the case assessment in Section 4, "Learning with Leonardo Da Vinci designs for Perpetual Motion Machines".

\subsection{PAIRS Component in Interaction Design}

The Augmented Reality for European Universities (AR-FOR-EU) project [12] is an EU funded project with the remit of designing and delivering a curriculum for universities on production of Augmented Reality experiences and applications. At its teacher training week, held in October 2019 at Oxford Brookes University, tutorials were given on User Interface and Experience (UI/UX) and the class discussed ways to classify design of interactions in AR. Based on the prior experience with this AR-FOR-EU project, as well as the case studies mentioned in this paper. It was proposed that interaction design could be implemented by mapping different types of interactions with the generated learning environment [13]. The acronym for the types of interactions was PAIRS and reflected that it interfaced between the ERDM and Contextology.

In discussions, the first author highlighted that in various applications and experiences worked with that there were five types of interactions that needed to be considered when designing user interfaces and user experience journeys.

1) Passive: A user might simply have an experience with no formal interaction, for example, they might watch a video, look at a work of art or put on a VR headset and see a model in 3D. These are examples where the engagement is Passive.

2) Active: The interface supports the user in taking an active role in unfolding an experience. This could be as simple as pressing a virtual button on a screen to change a passive object into an animated one, change the colour of a product, or choose more sophisticated activity sequences from precoded or pre-defined paths. E.g., click-through a virtual tour. Active objects can be built on lower level passive objects.

3) Interactive: The interface supports a two-way interactive experience between the user and the application. The outcome is uncertain. E.g., user trying to solve a step-by-step geometry problem with live assessment. An interactive experience can be built on lower level active elements.

4) Responsive: The interface provides interactivity and links the user with data that can go beyond the local application, in response to possible networked information or environmental activity. E.g. user consulting a virtual expert database while trying to repair a local machine while using AR-glasses. The experience may also change in response to signals or data from environmental sensors, an example being an infrared sensor triggering a projected animation on to the floor of an art installation. A responsive experience can be built on lower level interactive elements.

5) Shared: The interface supports shared experiences between people and groups of people. This is the hardest to achieve and can include the functionality of lower level responsive elements. E.g. Hololens used between groups of people so that they might study a model of a body simultaneously, seeing it from different perspectives, possibly while in different physical locations or places in the world.

\subsection{Typology of Contextology and Sensory Curation for TSF}

In order to reliably augment our perception across contexts, Contextology, creates collection of types of functions (a typology). This typology can be broken down into i) a Sense-based typology and ii) an Experiential typology. The Sense-based typology includes visual, audio, touch, smell, taste, etc., where new senses can be placed within a stack to work alongside the traditional senses. This is achieved by side-chaining something we can measure with technology to an existing sense. For example, we can use magnets to sense north and turn that into a touch signal, providing us with a North Sense [24]. Alternatively, we can measure activity going on inside the brain and turn that into an audio or vibratory signal. Of course, some context engineering opportunities are exploited / deployed by using several senses at once and/or by synergising certain senses together. The Experiential typology includes extrabody parameters (e.g. visual input from fingertip cameras), out of body components (selfie drone, airbnb of bodies), adapting inputs (e.g. resizing food, filtering out sounds, turning up the bass) and translating inputs (e.g. vagus nerve stimulators, audio to touch etc.).

\section{USE CASES OF TSF COMPONENTS}

Each of the TSF components has had their use represented in projects and case studies carried out since 2017. The TSF has been drawn from four key project/study areas, including the earlier described cases in fashion and architecture. Here we take an indepth look at two of the case study areas in art/design and in training.

Case Study: Learning with Leonardo Da Vinci designs for Perpetual Motion Machines

Leonardo Da Vinci, the Renaissance artist and engineer, died in 1519. In 2019, for the 500th Anniversary of Leonardo Da Vinci's death, many museums and institutions were prompted to curate exhibitions to celebrate his works. 
Da Vinci imagined machines that would run forever without an external fuel supply, perpetual motion machines as they are called in modern times. Some of the sketches and designs Da Vinci did of the machines he imagined are held in the Codex Atlanticus collection held at the Victoria and Albert museum in London. Examples of his designs from the collection are shown in Figure 3, showing two different wheel mechanisms kept in motion by the gravity of falling balls rolling within internal sections. Note his notes written in mirrored script.

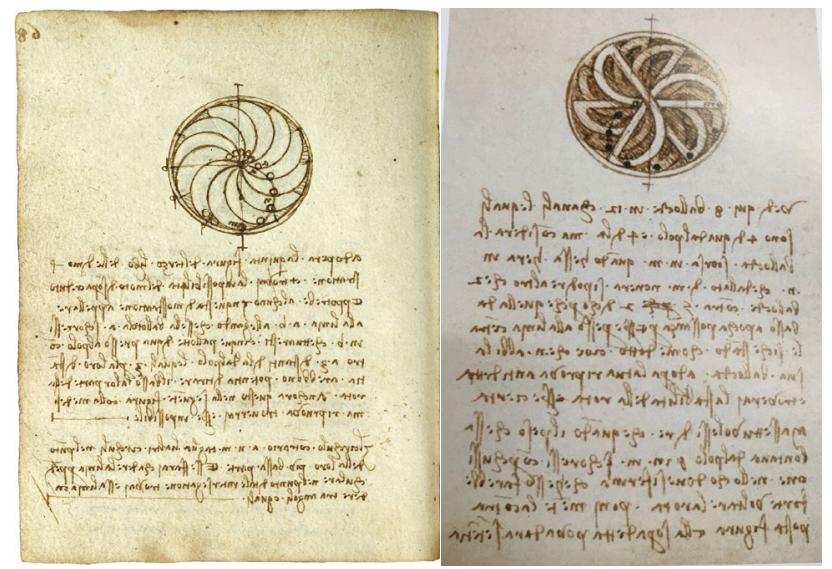

Figure 3. Leonardo Da Vinci's designs for perpetual motion machines. The Leonardo Da Vinci study created AR Target images from these sketches. They are an example of Captured Reality in the Eight Reality Design Methodology

A consortium came together to help curate works of Da Vinci's imagined, yet never modelled or built perpetual motion machines. The result was a design for an exhibition, initially to be held in London. The implemented exhibition was a collaboration between The Vasari Research Centre for Art and Technology at Birkbeck (London), Ravensbourne University London, The Museo Galileo (Florence); and with the support of the Leonardo da Vinci Society (London). It was also part of the international celebrations marking the 500th anniversary of the death of Leonardo da Vinci (14521519). Three exhibitions were held with installations at the Peltz Gallery in London [9], Victoria and Albert Museum in London [10] as well as the nucleus of a larger exhibition at the Museo Galileo in Florence (October 2019- January 2020) [11].

To provide modern experiences of his works it was proposed the machine designs could be explored within an exhibition. To ensure the right gamut of experiences accompanied the narrative behind the curation of works relating to Da Vinci's creative workflow, the scope of the desired experiences to be delivered was represented in an Eight Realities Perceptual Space, established by mapping the realities to be curated against the kinds of sensory channels to be engaged, within those mediums.

The overall dynamic of engaging specific patterns of senses in specific realities would define the response of visitors to the delivered experience, the Experience Response shown in Figure 4. The Sensory Channel column with question marks leaves open the possibility of including other types of Sense, perhaps Sense of Time or Space or even sensor data from electronic sensors providing extended or extra-sensory sensory perception. Note how Imaginary Reality is listed first here. There is some question as to which reality is the first one that creation takes place in, Everyday or Imaginary.

As can be seen from Figure 4. the sensory channel related to what people would See was going to have to be modelled most significantly. Specifically, it was important to see what Da Vinci held in his Imaginary Reality and how he documented his vision in the Captured Reality of his sketches. The project had to generate $3 \mathrm{D}$ models of the sketches. These would be 3D printed and used in the physical exhibition installation. Lastly, the sketches and their video animation as well as the $3 \mathrm{D}$ models were going to need to be seen in Augmented, Virtual and Holographic reality applications.

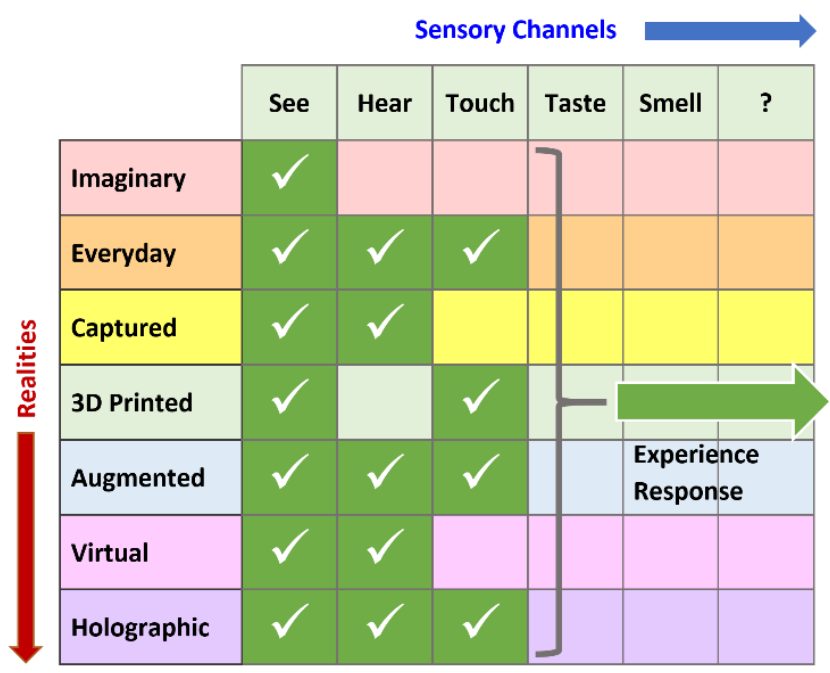

Figure 4. Mapping desired experience Realities and Sensory channels into an Eight Realities Perceptual Space (see ticked cells) that result in an Experience Response [19]

To accompany the experience, people would Hear audio captured, or generated that related to a voice over of the story as well as machine sounds to align with 3D model animations for Augmented, Virtual and Holographic versions of the experience. It was also felt, to increase immersion, that visitors should be able to Touch actual $3 \mathrm{D}$ printed designs and also manage progression of the narrative on tablet/smartphone devices through touchscreen or hand based gestures.

At this point, the inclusion of a framework and methodology, that explores how sensory channels are engaged with using technology, was sought in order to add a vital dimension to the Transreality Storyboarding Framework.

The Science of Context Engineering, Contextology was incorporated. Leonardo's research often looked at how perspective and perception could be experimented with. He explored mechanics and motion, how muscles moved and even how to represent images physically using technology. Linking mechanics and perception from Anatomy and Physiology to technology was utilised in the design of perpetual motion machine designs. Adopting Biological, Perceptual as well as Physiological traits for new innovations and perspectives is a central tenet of Context Engineering.

Mapping the interactions that mediate realities and sensory channels are expressed in the three TSF components as shown in Table 2.

The challenge for the curation of the Leonardo Da Vinci 500th Anniversary exhibitions was not just to create stand-alone experiences but also to ensure a coherent, engaging narrative arc across them that told Da Vinci's unfolding story from his original sketches to the modern mixed reality interpretations. The Eight Reality Design Methodology ensured that the exhibition would have at its root an exploration of Da Vinci's imagination and design mindset, process and techniques as well as serve the aim to 
seamlessly express it as a narrative to be experienced through different mediums, senses as well as interactions. The aspect of how visitors would interact within experiences, as mapped to PAIRS, could simply be of a passive nature or more hands on interactions.

\section{WEKIT, Design for Industrial Training. A learning experience in the project}

Wearable Experience for Knowledge Intensive Transfer (WEKIT) was a $€ 2.8 \mathrm{~m}$ EU funded project running 2015-2019, contributed to the interaction component of the TSF, PAIRS. WEKIT utilised Mixed Reality and Wearable Technology to capture knowledge and skills from Experts and transfer them to trainees in Aerospace, Space and Medical environments. The project produced content and assets in all eight realities with working practices focused on Augmented and Holographic Reality. The Software, Garments as well as real world biometric sensor systems were outcomes. The Software utilised shared experiences of digitally captured training previously recorded and uploaded to the Internet as well as biometric and environmental sensors. All categories of interactions in the PAIRS selection were incorporated. Visual, Audio and Haptic based assets were generated [15][16][17].Innovations that arose from WEKIT included fostering learning through the different perceptual affordances provided by Augmented and Holographic Reality experiences. Engaging in a workplace training task in a live way where the sense of time is linked to a sense of a real space while utilising virtual content are all themes that the Contextology framework provides.

In summary, four study areas are represented in Table 2 in terms of their use of TSF components.

Table 2. Case Studies and Their Use of TSF Components

Fashion: Couture in Orbit.(2017)

Prospective Garments to be worn by European Space Agency Astronauts in Space.

ERDM, Realities: Garments (Everyday), Designs of Garments (Imaginary/Captured) 3D Scans of Models (Captured), 3D Model of person from Scan (Computer Aided), Figures of Models (3D Print), Mobile and VR Headset experiences (Augmented and Virtual Reality)

PAIRS, Interactions: Passive viewing of Garments and 3D printed Models, Active viewing (triggered by Image Target) of 3D Scans in Augmented Reality.

Contextology Senses: Garments (Visual, Haptic), 3D Scans of Models (Visual), 3D Model of person from Scan (Visual), Figures of Models (Visual, Haptic), Mobile and VR Headset experiences (Visual)

Architecture: Application of AR and VR (2017)

Techniques to study the conservation of architectural heritage.

ERDM, Realities: Real World Buildings (Everyday), Architecture Designs (Imaginary/Captured), CAD Models (Computer Aided), Models of buildings (3D print), Building Walkthroughs, (Augmented, Virtual and Holographic)

PAIRS, Interactions: Passive viewing of buildings and 3D printed Models, Active viewing (triggered by Image Target) of 3D Scans of Buildings in Augmented Reality. Interactive walkthrough (Virtual Reality)

Contextology Senses: Buildings (Visual, Haptic), 3D Scans of Buildings (Visual), 3D Model of building/design from Scan or CAD model (Visual, Audio from Environment), Physical Models of buildings / designs. (Visual, Haptic), Mobile, VR and Hololens Headset experiences (Visual, Haptic)

Art/ Design: Leonardo Da Vinci (2018-2019)

Modern rendering of his Perpetual Motion Machine designs

ERDM, Realities: Museum Installation (Everyday), Sketches/Designs, Sound Effects, (Imaginary/Captured), CAD Models of Machines, Video animation of Machines (Computer Aided), Physical models of machines (3D print), Working Machine tour, (Augmented, Virtual and Holographic)

PAIRS, Interactions: Passive viewing of museum installation of Sketches, Videos and physical Models, Active viewing (triggered by Image Target) of 3D Models of machines in Augmented Reality. Interactive walkthrough (Virtual Reality/Holographic Reality), Online Download of AR app (Responsive/Shared)

Contextology Senses: Physical Machines (Visual, Haptic), CAD Model of machine/design, Video Animation (Visual, Audio Sound effects), 3D printed models of machines (Visual, Haptic),

Mobile, VR and Hololens Headset experiences (Visual, Audio, Haptic)

Training: WEKIT (2016-2019)

Workplace Training using Augmented, Virtual and Holographic Reality

ERDM, Realities: Site Installation in Aerospace, Space and Medical environments (Everyday), Sketches/Designs, Sound Effects of training equipment (Imaginary/Captured), CAD Models of Machines and Site artefacts, (Computer Aided), Physical parts for site equipment (3D print), Training site task experience, (Augmented, Virtual and Holographic)

PAIRS, Interactions: Passive viewing of at site installation of Sketches, Videos and physical Models, Active viewing (triggered by Image Target) of 3D Models of site equipment in Augmented Reality. Interactive walkthrough of lesson/training (Virtual Reality/Holographic Reality), Online Upload/Download of recorded training (Responsive/Shared)

Contextology Senses: Physical Equipment, garments, devices (Visual, Audio, Haptic), CAD Model of site equipment, Video capture/playback of task (Visual, Audio Sound effects), 3D printed parts for equipment (Visual, Haptic), Mobile, VR and Hololens Headset experiences (Visual, Audio, Haptic) 


\section{CONCLUDING REMARKS AND FUTURE WORK}

Storyboarding has traditionally been used in prototyping of film productions. This can now be extended as a technique with the three TSF components of ERDM, PAIRS and Contextology so that an expansive storyboarding strategy can be applied across all creative disciplines. The ambition of TSF is that it is used preemptively, prior to the initiation of any creative project, so the subsequent production will have the greatest likelihood of being concise in its narrative expression. That concise narrative expression should be achieved while additionally being precise in the use of the right type of media, technology as well as techniques. Future research will investigate the impact on learning of using the TSF in the effective expression of creative narrative.

Improvement to the TSF can be facilitated by mapping past creative works to the three parts of the TSF. This would involve selecting a diversity of completed or ongoing projects that collectively utilise all the realities of the ERDM, all five types of interaction within PAIRS as well as inferred use of Contextology to work on specific senses of audience members. Newly embarked projects can also benefit by mapping early stage designs to the TSF. The process of mapping completed, live and future projects to the TSF can highlight possible omissions, shortcomings as well as genuine capacity for utilisation and alignment to best practices. Iterative revision of TSF in this way can ensure it becomes a de-facto framework for creatives to use in their design, production and dissemination workflows.

\section{ACKNOWLEDGMENTS}

Our thanks to our colleagues in the cited projects for their inspirations.

\section{REFERENCES}

[1] Csikszentmihalyi, M. (1990). Flow: the Psychology of Optimal Experience. Harper Perennial.

[2] Logan, G. D., \& Crump, M. J. C. (2009). The left hand doesn't know what the right hand is doing: The disruptive effects of attention to the hands in skilled typewriting. Psychological Science, 20, 1296-1300.

[3] Pranantha, D. (2015). Experiments on flow and learning in games: creating services to support efficient serious games development Eindhoven: Technische Universiteit Eindhoven DOI: 10.6100/IR783192. (figures p.6)

[4] Nagalingam, V. and Ibrahim, R. (2015). "User Experience of Educational Games: A Review of the Elements." Procedia Computer Science 72, $423-433$.

[5] Jenkins, H. (2003). "Transmedia Storytelling." Technology Review. Last access February 13, 2014. Accessed 03.12.19, Online:

http://www.technologyreview.com/biomedicine/13052/.

[6] Jenkins, H. (2006). Convergence Culture: Where Old and New Media Collide, New York University Press, New York University.

[7] Dena, Christy. (2009). Transmedia Practice: Theorizing the Practice of Expressing a Fictional World Across Distinct Media and Environments - PhD thesis. Sydney: University of Sydney.

[8] O'Meara, R., Bevan, A. (2018). Transmedia Theory's Author Discourse and Its Limitations. Journal of Media Culture, Vol 21, No 1. Online: http://journal.media- culture.org.au/index.php/mcjournal/article/view/1366 Accessed: 03.12.19.

[9] Peltz Gallery, (2019). Leonardo da Vinci and Perpetual Motion: Visualising Impossible Machines, Peltz Gallery, London, UK.

http://www.bbk.ac.uk/linguistics/arts/research/peltzgallery/peltz-gallery-exhibitions-andevents/Visualising_Impossible_Machines

[10] Lambert, N., and Rasool, J. (2019). Leonardo Da Vinci and Perpetual Motion, Victoria and Albert Museum, London, UK. London Design Week, September 2019, https:/www.londondesignfestival.com/sites/default/files/ldf1 9_guide_web-use_2019.09.17-compressed.pdf

[11] Bernardoni, A., (2019). Leonardo Da Vinci and Perpetual Motion, Museo Galileo, Florence, Italy, https://www.museogalileo.it/en/museum/explore/temporaryexhibitions/1802-leonardo-da-vinci-and-perpetualmotion.html

[12] Augmented Reality for European Universities, Teacher Training, Oxford Brookes University, UK. (AR-FOR-EU), http://www.codereality.net

[13] Rasool, J., (2019). Proposal of PAIRS framework, Augmented Reality for European Universities, Teacher Training, Oxford Brookes University, UK. September 2019

[14] Gilbey, C., (2017). Couture in Orbit, 2017 International Conference on Apparel Textiles and Fashion Design, Sri Lanka, https://tinyurl.com/2017icatafd, https://tinyurl.com/2017icatafd-abstract, http://appareltextilesandfashiondesigning.globalacademicrese archinstitute.com/main/proceedings

[15] WEKIT Project, (2017). Accessed 17.12.19 at http://wekit.eu

[16] Wild, Fridolin (Ed.). (2017). Affordances for Capturing and Re-enacting Expert Performance with Wearables, Fridolin Wild et al, 12th European Conference on Technology Enhanced Learning (ECTEL 2017), http://wekit.eu/affordances-capturing-re-enacting-expertperformance-wearables/

[17] Ravagnolo, L., (Ed.). (2019). Enhancing Crew Training for Exploration Missions: the WEKIT Experience, AC19.B3.5.5, IAC 2019 https://iafastro.directory/iac/paper/id/50193/abstractpdf/IAC-19,B3,5,5,x50193.brief.pdf?2019-10-17.04:25:09

[18] Rasouli, I. (2017). Application of AR and VR techniques to the study of conservation of architectural heritage, UAE Modern Conference, Dubai Design Week, 14-15 Nov. 2017, https://www.dubaidesignweek.ae/programme/2017/conferenc e-uae-modern/

[19] Rasool, J., (2018). Breakfast Briefing: ‘ 8 Realities' - Future proofing the Creative Industries, https://tinyurl.com/futurecatapult2018, https://futurecities.catapult.org.uk/

[20] Wang, C., (2018) Using Transmedia Storytelling and Marketing to Increase Engagement with the David Owsley Museum of Art, Master of Arts Final Project submission, Ball State University, Indiana, USA

[21] Sellars, Paige E., (2019), "Dissent and Disruption: How Artists Redefine Museum Spaces and Audience Engagement".MAD-RUSH, Undergraduate Research 
Conference,

https://commons.lib.jmu.edu/madrush/2019/dissent/1

[22] Smith.C. H.(2014). Context Engineering Hybrid Spaces for Perceptual Augmentation. Electronic Visualisation and the Arts (EVA 2014) London, UK, Accessed, 06.01.20.

https://www.scienceopen.com/document_file/a4a3b0639424-4dba-8881-

4b2489d3c544/ScienceOpen/244_Smith.pdf
[23] Smith.C.H.(2016). Contextology - The Science of Context Engineering, Macquarie Learning Technology Research Cluster, Macquarie University, 27th October 2016.

https://wiki.mq.edu.au/pages/viewpage.action?pageId=22639 4118 .

[24] Holmes, K. (2016). An Artificial Cyborg Implant Has Been Fitted on Humans for the First Time. Design. 15 December 2016. Accessed 06.01.20.

https:/www.vice.com/en_uk/article/wnpvb5/cyborg-implantnorth-sense-fitted-on-humans 